\title{
EDITORIAL
}

\section{Subcortical Functions in Cognition}

\author{
Bruce Crosson $^{1,2}$
}

Accepted: 17 May 2021 / Published online: 22 July 2021

(C) This is a U.S. government work and not under copyright protection in the U.S.; foreign copyright protection may apply 2021

The role subcortical structures in cognition has been discussed for well over a century. In spite of the lingering consideration of the cerebellum and basal ganglia largely as structures with exclusively motor functions, consideration that they might participate in cognition has a lengthy history. Although in modern medicine, interest in cerebellar impact on intelligence can be traced to Malacarne's (1776) work (Schmahmann, 2019; Zanatta et al., 2018), the idea that the size of the cerebellum is related to a person's intelligence can be traced back to the ancient Greek physician Erasistratus (Zanatta, 2018). When Wallesch and Papagno (1988) reviewed the early literature about subcortical functions in language, they noted involvement of the following three luminaries. The first, Broadbent (1872), believed that the motor acts via which words are expressed occur in the basal ganglia. Wernicke (1874) expressed the belief that lesion of the left putamen and globus pallidus caused aphasia due to convergence of frontal projections there. Marie (1906) also believed subcortical structures to be involved in language.

Similarly, the thalamus was long believed to be a relay for information from the periphery to the brain (Sherman \& Guillery, 2006). Nonetheless, it is notable that in 1959, Penfield and Roberts wrote about a case of thalamic aphasia and speculated that the thalamus might play an integrative role in language. Intra-operative stimulation of thalamic nuclei also was shown to interrupt naming or even to evoke spoken language in some cases (see Crosson, 1984, for a review). However, the serious consideration of the thalamic functions in language awaited the invention and widespread utilization of the computerized (x-ray) tomography scan and later magnetic resonance imaging (MRI), then functional MRI (fMRI). The role of the thalamus in memory had a somewhat different course.

Bruce Crosson

bruce.crosson@emory.edu

1 Department of Neurology, Emory University, Atlanta, Georgia

2 Center for Visual and Neurocognitive Rehabilitation, Atlanta Veterans Affairs Medical Center, Decatur, Georgia
Although Gamper (1928) thought the mammillary bodies played a role in memory, it was the work of Victor et al. (1971) that invoked a role for the midline thalamus in memory, based on their autopsies of alcoholic Korsakoff's patients. Unlike language, though, work on the thalamus and memory could be carried on in animal models (e.g., Aggleton, 1986; Bachevalier et al., 1985; Mishkin, 1982).

Aided by the advent of three-dimensional structural neuroimaging, interest in the cognitive functions of subcortical structures began to build over the last several years of the twentieth century. In parallel, the growing interest in cognitive brain system theories overshadowed older localization approaches to brain functions. Over the past two decades or so, a growing body of research has emerged in the cognitive neuroscience literature on the role subcortical structures play in the brain's cognitive systems. This literature has been undergirded by several trends and is the main focus of articles in this special section.

One important trend involves the maturation of functional MRI as a tool for mapping cognitive functions onto brain systems as well as diffusion weighted MRI tractography for mapping connectivity between components of those functional systems. It has become common in this literature to see activity changes in the cerebellum, basal ganglia, and thalamus. However, frequently the literature is not designed to address the functions of these subcortical structures, making it difficult to interpret in that regard. The Clark et al. (2021) paper on the cerebellum in this special section discusses this difficulty in the context of their review. These authors explore how the cerebellum modulates cognitive functions, using attention deficit hyperactivity disorder and cerebellar tumors as models. Yet, the authors note the need for development of studies designed specifically to address how the cerebellum fits into brain systems to accomplish this modulation.

Further, this imaging literature often does not make distinctions between the various functional subunits within the subcortical structures, making it difficult to determine to which networks the subcortical activity implicates. In this special section, for example, Savage et al. (2021) focus 
specifically on the anterior, medial, and midline thalamus and the role of these structures in learning and memory, as well as in flexible adaptation. They focus on animal models of alcohol-use disorder that are carefully tailored to parallel this human disorder and to gain insight into its nature. Hence, the findings reviewed by these authors are critical to developing a detailed understanding of anterior, medial, and midline thalamic damage and its consequences in alcoholuse disorders.

Spurred by the growing availability of computers in the latter part of the twentieth century, parallel distributed processing (PDP) emerged as a highly influential form of computational neural network modeling. The development of this kind of modeling has been seen as bridging the gap between cognitive science and neuroscience and provided a means for constructing task-performing models (Kriegeskorte \& Douglas, 2018). In his work for the current collection of papers, Nadeau (2021) analyzed the role of the basal ganglia and thalamus in language through the lenses of parallel distributed processing principles and of evolution. Although he provided an in-depth analysis of the basal ganglia functions, his eventual assessment is that the basal ganglia play only a limited role in language. On the other hand, he concludes that there multiple potential roles for the thalamus in this uniquely human function.

Interest in the question of domain specific vs. domain general cognitive processes has increased in the cognitive neuroscience literature of the past couple of decades. In their review of the role of corticostriatal functions in language, Copland et al. (2021) took a rather different, but potentially complementary approach to that of Nadeau (2021). The former authors reviewed a large body of literature on the topic and concluded that the impact of the basal ganglia on language functions falls under the rubric of domain general processes. Specifically, they surmised that corticostriatal loops serve to respond to "uncertainty and conflict which demands selection, sequencing, and cognitive control."

A final recent trend represented in this special section on subcortical functions, is the major advances made in the definition of cortico-thalamo-cortical circuits and the physiology of the neurons comprising them. As in the Savage et al. (2021) paper, these discoveries rely on animal models. Yet, in his paper, Crosson (2021) uses these data to describe a potential role for these circuits in selection of words for spoken language, a uniquely human function. He incorporates a more limited subset of parallel distributed processing principles into his model than Nadeau (2021) discusses in his paper. Crosson posits an interplay between cortico-thalamo-cortical and cortico-cortical circuits that allows for the sculpting of iterative semantic-lexical processes resulting in relevant and optimal word choice during spoken language. Essentially, cortico-thalamo-cortical circuits are hypothesized to undergird this recurrent process with a stable semantic representation while cortico-cortical circuitry converts a semantic concept to lexical choices.

In summary, this special section for Neuropsychology Review discusses how cerebellar, basal ganglia, and thalamic structures participate in cognitive processes such as executive functions, memory, and language. The authors have provided up-to-date reviews with provocative hypotheses about the roles subcortical structures play in cognitive processes. We hope that readers will see both convergences and divergences between the conclusions reached by the various articles in this special section, which should provide rich fodder for experimental hypotheses to drive future conceptualization and research.

\section{References}

Aggleton, J. P. (1986). Memory impairments caused by experimental thalamic lesions in monkeys. Revue Neurologique, 142, 418-424.

Bachevalier, J., Parkinson, J. K., \& Mishkin, M. (1985). Visual recognition in monkeys: Effects of separate vs. combined transection of the fornix and amygdalofugal pathways. Experimental Brain Research, 57, 554-561.

Broadbent, W. H. (1872). On the cerebral mechanisms of speech and thought. Medico-Chirurgical Transactions, 55, 145-194.

Clark, S. V., Semmel, E. S., Aleksonis, H. A., Steinberg, S. N., \& King, T. Z. (2021). Cerebellar-subcortical-cortical systems as modulators of cognitive functions. Neuropsychology Review.

Copland, D., Brownsett, S., Iyer, K., \& Angwin, A. J. (2021). Corticostriatal regulation of language functions. Neuropsychology Review.

Crosson, B. (1984). The role of the dominant thalamus in language: A review. Psychological Bulletin, 96(3), 491-517. PMID: 6393180.

Crosson, B. (2021). The role of cortico-thalamo-cortical circuits in language: Recurrent circuits revisited. Neuropsychology Review.

Gamper, E. (1928). Zur frage der polioencephalitis haemorrhagic der chronischen alcoholiker. Anatomisch fefunde beim alkoholischen Korsakov undihre Beziehungen zum klinischen bild. Deutsche Aeitschrift Fur Nervenheilkunde, 102, 122-129.

Kriegeskorte, N., \& Douglas, P. K. (2018). Cognitive computational neuroscience. Nature Neuroscience, 21, 1148-1160.

Malacarne, V. (1776). Nuova esposinzione della vera struttura del cervelletto umano. Torino: G. Briolo.

Marie, P. (1906). Revision de la question de l'aphasie: Que faut-il penser des aphasies sous-corticales (aphasies pures)? La Semaine Medicale, 42

Mishkin, M. (1982). A memory system in the monkey. Philosophical Transactions of the Royal Society of London, (Series B: Biological Sciences), 298, 85-95.

Nadeau, S. E. (2021). Basal ganglia and thalamic contributions to language function: Insights from a parallel distributed processing perspective. Neuropsychology Review.

Penfield, W., \& Roberts, L. (1959). Speech and Brain Mechanisms. Princeton, NJ: Princeton University Press.

Savage, L. M., Nunes, P. T., Fursky, A. H., Milbocker, K. A., \& Klintsova, A. Y. (2021). Midline thalamic damage associated with alcohol-use disorders: Disruption of distinct thalamocortical pathways and function. Neuropsychology Review.

Schmahmann, J. D. (2019). The cerebellum and cognition. Neuroscience Letters, 688, 62-75. 
Sherman, S. M., \& Guillery, R. W. (2006). Exploring the Thalamus and Its Role in Cortical Function (2nd ed.). The MIT Press.

Victor, M., Adams, R. D., \& Collins, G. H. (1971). The WernickeKorsakoff Syndrome. F. A. Davis.

Wallesch, C.-W., \& Papagno, C. (1988). Subcortical aphasia. In F. C. Rose, R. Whurr, \& M. A. Wyke (Eds.), Aphasia (pp. 256-287). Whurr Publishers.

Wernicke, C. (1874). Der Aphasie Symptomencomplex. Breslau: Cohn and Weigert.
Zanatta, A., Cherici, C., Bargoni, A., Buzzi, S., Cani, V., Mazzarello, P., \& Zampieri, F. (2018). Vencenzo Malacarne (1744-1816) and the first description of the human cerebellum. The Cerebellum, $17,461-464$.

Publisher's Note Springer Nature remains neutral with regard to jurisdictional claims in published maps and institutional affiliations. 